IZA DP No. 4173

Equal-Treatment Policy in a Random Search Model with Taste Discrimination

Leo Kaas

Jun Lu

May 2009 


\title{
Equal-Treatment Policy in a Random Search Model with Taste Discrimination
}

\author{
Leo Kaas \\ University of Konstanz \\ and IZA \\ Jun Lu \\ University of Konstanz
}
Discussion Paper No. 4173
May 2009

IZA
P.O. Box 7240
53072 Bonn
Germany

Phone: +49-228-3894-0

Fax: +49-228-3894-180

E-mail: iza@iza.org

\begin{abstract}
Any opinions expressed here are those of the author(s) and not those of IZA. Research published in this series may include views on policy, but the institute itself takes no institutional policy positions.

The Institute for the Study of Labor (IZA) in Bonn is a local and virtual international research center and a place of communication between science, politics and business. IZA is an independent nonprofit organization supported by Deutsche Post Foundation. The center is associated with the University of Bonn and offers a stimulating research environment through its international network, workshops and conferences, data service, project support, research visits and doctoral program. IZA engages in (i) original and internationally competitive research in all fields of labor economics, (ii) development of policy concepts, and (iii) dissemination of research results and concepts to the interested public.
\end{abstract}

IZA Discussion Papers often represent preliminary work and are circulated to encourage discussion. Citation of such a paper should account for its provisional character. A revised version may be available directly from the author. 
IZA Discussion Paper No. 4173

May 2009

\section{ABSTRACT \\ Equal-Treatment Policy in a Random Search Model with Taste Discrimination}

We consider a search model of the labor market with two types of equally productive workers and two types of firms, discriminators and non-discriminators. Without policy intervention, there is wage dispersion between and within the two worker groups, but all wage differences become negligible when the taste for discrimination is small. We analyze the effect of an equal-pay policy, both in combination with affirmative action and without. When equal opportunity of hiring cannot be enforced, wage dispersion increases and wages for minority workers fall substantially relative to laissez faire. Sometimes also the wage gap between worker groups widens in response to the policy.

JEL Classification: $\quad \mathrm{J} 41, \mathrm{~J} 71, \mathrm{~J} 78$

Keywords: $\quad$ search model, wage dispersion, discrimination, equal pay policy

Corresponding author:

Leo Kaas

Department of Economics

University of Konstanz

78457 Konstanz

Germany

E-mail: leo.kaas@uni-konstanz.de 


\section{Introduction}

There are persistent wage gaps between demographic groups that cannot be related to observable productivity differences. Many researchers and policy makers attribute such gaps to discriminatory behavior of employers. It is therefore not surprising that several countries have implemented legislation to combat discrimination in the labor market. In principle two types of equal-treatment policies can be distinguished. There are equal pay laws, demanding equal remuneration for equal work, and there are equal employment opportunity laws, covering hiring and promotion practices. But even in the United States, where such legislation has been introduced more than forty years ago, considerable earning gaps between races and genders remain, and the evidence on the impact of equal-treatment policy on inequality is mixed.1] This paper analyzes the effectiveness of equal-treatment policy in a search model where a wage differential between two groups of equally productive workers arises due to a discriminatory taste of a fraction of employers. Prejudice on the side of employers (or co-workers/customers) is one of the two prominent theoretical explanations for labor market discrimination which goes back to Becker (1957) 2 It is a well known result that taste-based discrimination can only occur temporarily but not permanently if all goods and factor markets are perfectly competitive (see e.g. Cain (1986)). In light of such findings, one may be tempted to conclude that there is no need for policy combating discrimination; to the contrary, market deregulation alone will be enough to throw discriminating employers out of business.

Yet, today there is broad agreement between labor economists that the competitive, frictionless model is inadequate to deal with many labor market phenomena, such as unemployment and wage dispersion. Search and matching models are the most common alternative (see Rogerson, Shimer, and Wright (2005) for a recent

\footnotetext{
${ }^{1}$ Exploiting state-level variation in anti-discrimination statutes, Neumark and Stock (2001) show that there is no evidence of a positive effect of equal-treatment legislation on relative earnings of black males, although there seems to be a modest positive effect on the earnings of black females relative to white males.

${ }^{2}$ The other is statistical discrimination (Phelps (1972) and Arrow (1973)) which is not considered here.
} 
overview), and these models have also been used to address discrimination; see the literature overview below. However, although wage gaps between equally productive workers can persist in frictional labor markets, policy conclusions are far from obvious. Conventional wisdom suggests the usual trade-off between equality and efficiency, so that it is up to the political preferences of society to decide the appropriate strength of anti-discrimination enforcement. In this paper, we argue that this intuition can go wrong: in many circumstances equal-pay policy can both harm equality and efficiency.

We consider a Burdett and Judd (1983) model of the labor market, with two groups of workers (A and B) and two types of firms, some with a discriminatory taste against type $\mathrm{B}$ workers. Without policy intervention, the equilibrium exhibits a positive wage gap between the two worker groups and there is also within-group wage dispersion. By assuming that each worker sends several applications, we ensure that inequality is negligible if the disutility taste is small. In fact, our model gives rise to the perfectly competitive (Bertrand) outcome in the absence of discriminatory behavior, but to non-competitive outcomes otherwise. We then discuss two types of equal-treatment legislation. On the one hand, there is an equal-pay law (EPL) which requires that any firm pays the same wage to its workers (who are all employed in the same occupation). We assume throughout that this policy can be enforced perfectly. On the other hand, there is an equal employment opportunity law (EEOL) which requires that any firm's workforce must represent the population shares of the two worker groups sufficiently 3 Here we contrast two opposite scenarios. In the first, EEOL can be perfectly enforced. Unsurprisingly, in such situations the combination of the two policy measures reduces the wage gap to zero, although some withingroup wage dispersion still remains.

The other scenario is the complete absence of EEOL, or, equivalently, the impossibility to enforce such legislation. Certainly, in practice there are enforcement problems for both equal-pay and equal-employment laws. The policy regime where EPL op-

\footnotetext{
${ }^{3}$ In the U.S., EPL is embodied in the Equal Pay Act of 1963, and EEOL is formulated in title VII of the Civil Rights Act of 1964, and enforced by the Equal Employment Opportunity Commission (EEOC), established in 1965.
} 
erates effectively and EEOL does not is clearly an abstraction; it reflects the view that equality of employment opportunities is perhaps more difficult to enforce than equality of pay within the same firm. Indeed, non-compliant behavior is hard to monitor and punish; private firms can easily decide not to invite unfavored job applicants for an interview without being charged with violation of EEOL. Affirmative action and employment quotas are, if at all, applied to a small segment of the labor market only, such as public employers or government contractors 4 There is also direct evidence of hiring discrimination from field experiments, which further supports the view that enforcement of equal employment opportunity is far from perfect 5

The main result of this paper is that the combination of EPL without perfect enforcement of EEOL increases inequality dramatically; relative to laissez faire, wage dispersion unambiguously increases and mean wages for minority workers generally fall. Because also wages for majority workers are lower, the effect on the mean wage gap between the two worker groups is ambiguous. Nevertheless, we also demonstrate that the wage gap can even increase in reaction to equal pay policy, particularly in labor markets where the number of minority workers is low and the number of discriminating employers is large. The intuition for the adverse policy impact on inequality is as follows. Some discriminating employers who are not allowed to discriminate in pay decide to discriminate in hiring. Hence minority workers receive fewer job offers, so that their labor supply becomes less elastic than the labor supply of majority workers. In turn, the firms' wage competition becomes less fierce, wage-offer distributions shift to the left, with a support that is much larger than under laissez faire. We also find that not all discriminating firms discriminate in hiring: there are high-wage firms who reject minority applicants but at the same

\footnotetext{
${ }^{4}$ In the U.S., all firms with more than 100 employees are required to submit employment reports to the EEOC who is authorized to initiate lawsuits on the basis of underrepresentation of minorities. However, such lawsuits are rare (Holzer and Neumark (2000)), and firms who want to discriminate against some group (e.g. black males) can easily circumvent the EEOC requirements by hiring more members of another protected group (e.g. white females). For evidence on this last issue, see Bisping and Fain (2000).

${ }^{5}$ For the U.S., see e.g. the audit study of Neumark et al. (1996) and the correspondence test of Bertrand and Mullainnathan (2004). See also the survey of Riach and Rich (2002).
} 
time low-wage firms who hire them despite their distaste.

There are other contributions exploring discrimination in search models. In the model of Black (1995), minority workers receive lower wages because it is assumed that these workers do not receive job offers from discriminating employers. In contrast, in our model employment discrimination does not occur under laissez faire; it is the endogenous equilibrium response to the equal-pay policy, and there are also discriminating firms who make wage offers to minority workers, albeit at low wages. Closely related to our model is Bowlus and Eckstein (2002) who consider taste discrimination in a Burdett and Mortensen (1998) model of the labor market, both with and without equal-pay legislation. They also show that this policy does not eliminate wage gaps, but again they assume that minority workers are discriminated in hiring, uniformly across all disutility firms. Our model, in contrast, derives hiring strategies endogenously and they are not uniform across firms. In contrast to these wage-posting models, Rosen (2003) considers a model with wage bargaining and finds that discriminating firms can achieve higher profits than nondiscriminating firms, thus arguing that discriminating employers are more likely to survive in the long run. In our model, as in the others discussed above, this is not the case: discriminating employers earn lower profits than nondiscriminating employers. Nevertheless, we show that discriminators' profits can increase in response to the policy. Finally, Lang, Manove, and Dickens (2005) consider a model where search is directed rather than random. Assuming that firms cannot discriminate in pay, a non-negligible wage gap arises even when the disutility taste is arbitrarily small. In their model, all firms have discriminatory preferences, ranking majority applicants before minority applicants. Minority workers do not apply to firms posting high wages where hiring chances are very low since only these jobs attract majority applicants. In equilibrium, thus, complete market segregation arises. However, firms rarely post wages publicly in the real world, and although segregation is a prevalent phenomenon, it is far from perfect 6

\footnotetext{
${ }^{6}$ Shi (2006) also discusses between-group wage inequality in a directed search framework. He argues that actual wage differentials among similar workers may not be a valid indicator of discrimination. What really matters are expected wages which include job-finding chances.
} 
Of course our paper is not the first pointing at adverse impacts of equal-treatment policies. Welch (1976) argues that equal-treatment policy entails allocative efficiency losses, but this is little surprising given that there are no frictions in his model. On the other hand, Lundberg and Startz (1983) show that in a model of statistical discrimination, an equal-pay policy can raise welfare by inducing minority workers to invest more in their human capital. By contrast, Coate and Loury (1993) argue that affirmative-action policies do not necessarily promote equality because of a patronization problem: protected workers anticipate that their employment chances are good even if they do not invest in productive skills. Our mechanism is much more basic; it simply describes the labor market response to equal-treatment policy, abstracting from any long-run effects on human capital investment 7

The remainder of the paper is organized as follows. The next section introduces the model. Section 3 derives equilibrium without policy regulation, and Section 4 discusses the scenario where equal pay policy is combined with strict affirmative action. Section 5 considers the effect of an equal-pay policy when equal opportunity of employment cannot be enforced. Section 6 analyzes the policy impact on mean wages and on the wage gap in numerical examples. Section 7 concludes.

\section{The Model}

We consider a Burdett and Judd (1983) model of the labor market, with heterogenous workers and with a discriminatory taste disturbing the preferences of some employers. There is a continuum $[0,1]$ of workers divided into two types; fraction $(1-\sigma)$ are type $\mathrm{A}$ and fraction $\sigma$ are type $\mathrm{B}$ workers. Both worker types are nonnegligible, i.e. $\sigma \in(0,1)$. When employed, all workers have the same productivity $p>0$ and the reservation wage is common to all workers and normalized to zero.

There is a large number $N$ of firms, each of which can hire an arbitrary number of workers to produce output $p$ per worker. Fraction $\lambda$ of firms are "disutility firms"

\footnotetext{
${ }^{7}$ Kaas (2009) finds similar effects of equal-pay policy in a spatial labor market model of monopsonistic competition.
} 
who derive linear disutility $d$ for every B worker in their workforce. These firms maximize profit net of disutility from B employment. The disutility taste is low enough so that these firms are willing to hire B workers at a sufficiently low wage; that is, $d<p$. The remaining $(1-\lambda) N$ firms are conventional profit maximizers; they are indifferent between hiring $\mathrm{A}$ or $\mathrm{B}$ workers. We assume that $N$ is such a large number that each firm, regardless of its type, perceives (approximately) that a fraction $\lambda$ of its competitors are again disutility firms. Importantly, although each firm is small relative to its competitors, it is large relative to workers; particularly, each firm ends up employing an infinity of workers.

In the absence of policy regulation (laissez faire), the sequence of events is as follows.

Stage I Every worker applies at exactly $1+m$ random firms, where $1 \leq m \ll N$ is exogenously given.

Stage II Every firm $j$ offers jobs at wage $w_{A}^{j}$ to A applicants and at wage $w_{B}^{j}$ to B applicants.

Stage III Workers accept the best offer as long as the offer is at least as high as their zero reservation wage. If a worker has two or more equal offers, he accepts any of them with the same chance.

Four remarks are in order. First, although firms offer wages after workers apply, this framework is equivalent to one where firms commit to wages before the application stage and where search is random, as is the case in Burdett and Judd (1983). Second, the firms' wage policies are restricted to rule out within-group wage discrimination. This is not a critical requirement. Even if firms were allowed to wage discriminate between workers of the same type, they need not exercise this option 8 Third, the

\footnotetext{
${ }^{8}$ Although it may happen that firms are indifferent between several wage offers, the assumption that there is no within-firm wage dispersion (among workers of the same type) restricts the equilibrium set only trivially. All wage dispersion, if any, happens across firms in this model. This is also in line with the empirical regularity that most wage dispersion is between firms rather than within firms.
} 
assumption that each worker sends $1+m \ll N$ applications (rather than applying at all firms) captures the search frictions in this model which eventually gives rise to non-competitive wages. Note that when all workers and jobs are identical (which is the case when $d=0$ or $\sigma=0$ or $\lambda=0$ ), two or more applications are enough to yield the perfectly competitive outcome through Bertrand wage competition 9 Otherwise, however, firms can exercise market power, wages for B workers differ from their marginal product, and there is wage dispersion. Fourth, the actual number $N$ turns out to be irrelevant for equilibrium since there are no capacity constraints at any firm.Instead, the appropriate measure of the strength of competition in this model is the number of applications per worker. Indeed, it is reasonable to imagine that $1+m$ increases proportionately with the number of active firms 10

At the second stage, firms maximize their payoff by setting wages for A workers and $\mathrm{B}$ workers respectively, taking the wage offer distributions of competitors as given. The payoff of a nondisutility firm offering wages $\left(w_{A}, w_{B}\right)$ is simply its profit

$$
\left(p-w_{A}\right) l^{A}\left(w_{A}\right)+\left(p-w_{B}\right) l^{B}\left(w_{B}\right)
$$

where $l^{s}\left(w_{s}\right)$ is labor supply of type $s=A, B$ workers to a particular firm offering wage $w_{s}$. The payoff of a disutility firm offering $\left(w_{A}, w_{B}\right)$ is profit minus linear disutility of B employment:

$$
\left(p-w_{A}\right) l^{A}\left(w_{A}\right)+\left(p-d-w_{B}\right) l^{B}\left(w_{B}\right)
$$

Since search is random, the number of applications of workers of a given type at any firm is the same. Consequently, expected employment of A (or B) workers only depends on the wage offer but is independent of the firm type. Let $F_{d}^{s}\left(w_{s}\right)$ and $F_{n}^{s}\left(w_{s}\right)$ denote the cumulative wage offer distributions to workers of type $s=A, B$

\footnotetext{
${ }^{9}$ This is Lemma 2(ii) of Burdett and Judd (1983). If workers would send only one application with positive probability less than one, there would be wage dispersion even with homogenous workers.

${ }^{10}$ For example, think of a spatial model where workers live in an area of size $L$ and that each worker applies at all firms in a region of size $\varepsilon L$ around his home. If firms are uniformly distributed across area $L$, each worker applies at $1+m \approx \varepsilon N$ firms.
} 
by disutility and nondisutility firms, respectively. Then employment levels of A and B workers at a firm offering $\left(w_{A}, w_{B}\right)$ are 11

$$
\begin{aligned}
& l^{A}\left(w_{A}\right)=\frac{(1+m)(1-\sigma)}{N}\left[\lambda F_{d}^{A}\left(w_{A}\right)+(1-\lambda) F_{n}^{A}\left(w_{A}\right)\right]^{m}, \\
& l^{B}\left(w_{B}\right)=\frac{(1+m) \sigma}{N}\left[\lambda F_{d}^{B}\left(w_{B}\right)+(1-\lambda) F_{n}^{B}\left(w_{B}\right)\right]^{m} .
\end{aligned}
$$

For example, in the first equation, $\frac{(1+m)(1-\sigma)}{N}$ is the mass of A workers applying at a particular firm, and the expression [. $]^{m}$ is the share of these applicants whose remaining $m$ offers are all not larger than $w_{A}$.

\section{Laissez-faire equilibrium}

Since firms' payoffs are separable in the two employment types, stage-II wage competition can be solved separately for A and B workers.

Each A worker sends at least two applications and thus gets several wage offers from equally productive firms. Therefore, firms bid up wage offers to the workers' marginal product. The unique equilibrium wage offer distribution is the degenerate distribution that has all mass concentrated at $w_{A}=p$ (Bertrand equilibrium) 12

Clearly, the wage offer distribution function for B workers differs from the one for A workers, since some firms derive a disutility taste when employing B workers. While disutility firms bid wage offers up to their "effective" marginal product $p-d$, the full wage offer distribution does not degenerate at that value. Nondisutility firms realize that some of their B applicants obtain all other offers from disutility firms at $w=p-d$ while other $\mathrm{B}$ applicants obtain offers from nondisutility firms that can profitably hire this worker at higher wages. Hence nondisutility firms face a trade-off between low wage costs and higher recruitment rates which gives rise to

\footnotetext{
${ }^{11}$ For simplicity, all distribution functions in these expressions are continuous. Whenever there are mass points, the employment terms must be altered according to stage III randomization between equal offers.

${ }^{12}$ It is trivial that the competitive wage is an equilibrium. Uniqueness follows from Lemma 2(ii) of Burdett and Judd (1983).
} 
wage dispersion, as in the static model of Burdett and Judd (1983), or in dynamic models with search-on-the-job like Burdett and Mortensen (1998).

Since the wage offer distribution $F_{d}^{B}$ degenerates at $p-d$, the lower bound of distribution $F_{n}^{B}$ must be equal to $p-d$ : no nondisutility firm will attract any worker by offering $w<p-d$; and if the lower bound of the support of $F_{n}^{B}$ was at $\underline{w}>p-d$, the firm offering $\underline{w}$ would hire the same number of B workers at lower cost at wage offer $\underline{w}-\varepsilon>p-d$. On the other hand, no nondisutility firm will exactly offer $p-d$ since it can attract share $\lambda^{m} /(1+m)$ of all $\mathrm{B}$ applicants at this wage (share $m \lambda^{m} /(1+m)$ of them will go to a disutility firm offering the same wage and share $1-\lambda^{m}$ go to a nondisutility firm offering a higher wage), whilst it hires at least share $\lambda^{m}$ of all B applicants at any slightly larger wage. In other words, the payoff function of nondisutility firms jumps upwards at $w=p-d$. Using standard arguments, one can also show that the distribution of wage offers of nondisutility firms cannot have mass points and must be strictly increasing. Hence the support of $F_{n}^{B}$ is a connected, half-open interval $\left(p-d, \bar{w}^{B}\right]$.

To find the equilibrium distribution, we make use of the indifference condition which states that any wage $w \in\left(p-d, \bar{w}^{B}\right]$ yields the same expected payoff as a wage offer arbitrarily close to, but above $p-d$ :

$(p-w) l^{B}(w)=(p-w) \frac{(1+m) \sigma}{N}\left[\lambda+(1-\lambda) F_{n}^{B}(w)\right]^{m}=[p-(p-d)] \frac{(1+m) \sigma}{N} \lambda^{m}$.

Solving yields the unique equilibrium wage offer distribution of nondisutility firms for B workers:

$$
F_{n}^{B}(w)=\frac{\lambda}{1-\lambda}\left[\left(\frac{d}{p-w}\right)^{1 / m}-1\right]
$$

which has upper bound $\bar{w}_{B}=p-d \lambda^{m}$. Hence, the market wage offer distribution for $\mathrm{B}$ workers is

$$
F^{B}(w)=(1-\lambda) F_{n}^{B}(w)+\lambda F_{d}^{B}(w)=\left\{\begin{array}{l}
0 \quad, w<p-d \\
\lambda\left(\frac{d}{p-w}\right)^{1 / m}, w \in\left[p-d, p-d \lambda^{m}\right]
\end{array}\right.
$$

Proposition 1: Under laissez-faire, the unique equilibrium wage offer distribution for $A$ workers degenerates at $w=p$. The wage offer distribution for $B$ workers is 
non-degenerate with support $\left[p-d, p-d \lambda^{m}\right]$ and cumulative distribution (11). All $B$ workers earn lower wages than $A$ workers. A disutility firm obtains zero payoff and positive profit $\sigma d \lambda^{m} / N$, and a nondisutility firm earns profit $(1+m) \sigma d \lambda^{m} / N$. Every nondisutility firm employs more $B$ workers than any disutility firm.

In contrast to a perfectly competitive labor market, a discriminatory taste of some firms together with search frictions affects the shape of the wage offer distributions which exhibits both between-group and within-group (group B only) wage dispersion. Note however that all wage dispersion disappears in the limit $d \rightarrow 0$. Another "competitive limit" obtains when $m \rightarrow \infty$. Although the wage-offer distribution is still non-degenerate in the limit (it has mass points at $p-d$ and at $p$ ), the earnings distribution is not: all $B$ workers are employed at nondisutility firms at wage $w=p$. As in Becker's model, segregation eliminates any wage differentials in a competitive labor market.

\section{Equal pay with strict affirmative action}

Suppose now the government imposes an equal-pay law that prohibits wage differentials in identical occupations within the same firm. Suppose furthermore that there is a perfectly enforceable equal-employment-opportunity law which stipulates that each firm must employ at least as many B workers in relation to its A workers as corresponds to the relative population share. Alternatively, the law regulates that the $\mathrm{B}-\mathrm{A}$ ratio of new hires is not lower than this ratio in the firm's application pool. But this second requirement is identical to the first in the random search environment of this model. In any case, the legislation prescribes that the ratio between $\mathrm{B}$ and $\mathrm{A}$ employment in any firm may not fall short of $\sigma /(1-\sigma) 13$

Under this policy regime, each firm can offer only one wage to both types of workers and it cannot reject any B applicant whenever it hires all its A applicants. Formally,

\footnotetext{
${ }^{13} \mathrm{~A}$ more general policy would be the requirement that each firm respects the constraint $\ell^{B} / \ell^{A} \geq$ $\gamma \sigma /(1-\sigma)$ with some $\gamma \in[0,1]$ measuring the strength of affirmative action. This section considers the extreme $\gamma=1$, whilst the next section focuses on the absence of affirmative action where $\gamma=0$.
} 
the second stage of our model is altered as follows.

Stage II Every firm decides a common wage $w$ for all its workers. It may offer this wage to as many applicants as it wants, but the ratio between $\mathrm{B}$ and $\mathrm{A}$ workers may not fall short of $\sigma /(1-\sigma)$.

Clearly, a nondisutility firm hires all applicants at any wage $w<p$. If a disutility firm hires $\ell$ workers at wage $w$, its payoff is $(p-\sigma d-w) \ell$ since fraction $\sigma$ of its workers must be of type B. Hence, a disutility firm decides to hire all applicants at any wage $w<p-\sigma d$, but it is unwilling to hire any worker at a wage $w>p-\sigma d$. Put differently, $p-\sigma d$ is the marginal payoff of an additional worker for a disutility firm in this policy regime. We assume that disutility firms hire all applicants at wage $w=p-\sigma d$, although they are indifferent between all legal hiring strategies at this wage.

Similar to the laissez-faire case, there is again perfect wage competition between disutility firms who bid their wage offers up to their effective marginal product $p-\sigma d$. On the other hand, the wage offer distribution of nondisutility firms does not degenerate. The positive probability that an applicant gets all other offers from disutility firms at $p-\sigma d$ gives these firms some market power, so that they randomize wages from a common distribution whose lower bound is at $p-\sigma d$.

In the mixed-strategy equilibrium, nondisutility firms are indifferent between any wage $w$ in the support of the wage offer distribution and a wage arbitrarily close to the lower bound $p-\sigma d$ :

$(p-w)\left[l^{A}(w)+l^{B}(w)\right]=(p-w) \frac{1+m}{N}\left[\lambda+(1-\lambda) F_{n}(w)\right]^{m}=[p-(p-\sigma d)] \frac{1+m}{N} \lambda^{m}$.

Solving yields the equilibrium wage offer distribution of nondisutility firms:

$$
F_{n}(w)=\frac{\lambda}{1-\lambda}\left[\left(\frac{\sigma d}{p-w}\right)^{1 / m}-1\right]
$$

whose upper bound is $p-d \sigma \lambda^{m}$. The market wage offer distribution, i.e. the fraction of all firms paying $w$ or less to both types of workers, is $F(w)=\lambda F_{d}(w)+(1-$ 
$\lambda) F_{n}(w)$,

$$
F(w)=\left\{\begin{array}{l}
0 \quad, w<p-d \sigma, \\
\lambda\left(\frac{\sigma d}{p-w}\right)^{1 / m}, w \in\left[p-d \sigma, p-d \sigma \lambda^{m}\right] .
\end{array}\right.
$$

Comparison with (11) shows that the wage-offer distribution first-order stochastically dominates the distribution for B workers under laissez-faire. Therefore, the mean wage for $\mathrm{B}$ workers is higher while the mean wage for A workers is lower under the policy. Obviously, the wage differential between the different demographic groups is totally eliminated. Perhaps surprisingly, profits for all firms are unchanged relative to laissez-faire.

Proposition 2: Under the equal-pay policy with strict affirmative action, the equilibrium wage offer distribution has support $\left[p-\sigma d, p-\sigma d \lambda^{m}\right]$ and cumulative distribution (2) which stochastically dominates wage offers for B workers under laissez-faire. Mean wages for $A$ and $B$ workers are equalized. Disutility firms obtain zero payoff and positive profit $\sigma d \lambda^{m} / N$, and nondisutility firms earn profit $(1+m) \sigma d \lambda^{m} / N$, the same as under laissez-faire.

\section{Equal pay without affirmative action}

When combined with strict affirmative action, equal-pay legislation succeeds in eliminating wage differences between worker groups. However, such an ideal result obtains only if the employers are not allowed to discriminate in hiring by rejecting less attractive job applicants. That is, equal opportunity of employment must be perfectly enforced. As we have argued in the introduction, there are several reasons why this may not be the case. We thus explore the situation where equal-pay policy works effectively while hiring discrimination cannot be prohibited. The key question is whether the policy is still effective in lowering wage inequality and raising wages for B workers. We now have

Stage II Every firm decides a common wage $w$ for all its workers. It may offer this 
wage to as many applicants as it wants.

In this alternative policy scenario, a disutility firm decides to hire all applicants at any wage offer $w<p-d$ but it rejects all $\mathrm{B}$ applicants at any wage offer $w>p-d$. Consequently, the equilibrium outcome of Proposition 2 cannot be sustained anymore. Particularly, at their equilibrium wage offer $p-\sigma d$, all disutility firms would reject as many B applicants as possible. This also implies that there must be hiring discrimination in equilibrium, i.e. some disutility firms must offer wages $w>p-d$ and reject $\mathrm{B}$ workers. For if this was not the case, hiring behavior would be the same as in the previous section; fierce wage competition would set in again so that, at some point, all firms will offer wages above $p-d$ which, in turn, must induce disutility firms to reject B applicants.

Since some B applications get rejected, all firms gain market power and are inclined to change their pay policy; anticipating that some workers do not obtain another offer, they are able to attract at least a few B workers by merely offering the reservation wage. Indeed, in stark contrast to our previous results, the lower bound of the wage offer distribution is now at zero.

Because the possibility of hiring discrimination affects B workers only, labor supply of B workers to any firm is generally less elastic than labor supply of A workers. For this reason, a nondisutility firm offers a lower wage than a disutility firm who offers $w>p-d$ and attempts to hire only A workers whose labor supply is more elastic. Indeed, it turns out that the highest wages are offered by disutility firms that hire only A workers. Sometimes, however, a fraction of disutility firms do not reject $B$ workers and offers wages which are even lower than the wages offered by nondisutility firms. This is intuitively easy to explain: the marginal payoff of an additional worker is larger at a nondisutility firm than at a disutility firm that hires all workers. These results can be formally stated in the following Lemma which is proven in the Appendix.

Lemma: Let $F=\lambda F_{d}+(1-\lambda) F_{n}$ be the equilibrium distribution of wage offers. Then $F$ is strictly increasing and continuous (that is, there are no holes and no 
mass points) and the lower bound of the support is at the workers' reservation wage of zero. Moreover, for any $w_{n}$ in the support of $F_{n}$ and $w_{d}^{i}, i=1,2$, in the support of $F_{d}$ such that $w_{d}^{1} \leq p-d<w_{d}^{2}$, it holds that $w_{d}^{1} \leq w_{n} \leq w_{d}^{2}$.

From this Lemma follows that equilibrium can be described as follows. There are wage thresholds $0 \leq \underline{w}_{0} \leq p-d<\underline{w}_{1}<\bar{w}<p$ and a number $\mu \in[0,1)$ such that:

1. Fraction $\mu$ of disutility firms make low wage offers, drawn from distribution $F_{d}^{l}$ with support $\left[0, \underline{w}_{0}\right]$. These firms hire all applicants.

2. Nondisutility firms draw wage offers from distribution $F_{n}$ which has support $\left[\underline{w}_{0}, \underline{w}_{1}\right]$, and they hire all applicants.

3. Fraction $1-\mu$ of disutility firms make high wage offers, drawn from distribution $F_{d}^{h}$ with support $\left[\underline{w}_{1}, \bar{w}\right]$. These firms hire only A applicants.

In the Appendix (proof of Proposition 3) we characterize the equilibrium wage-offer distribution. For given $\mu$, one can derive $F$ and the critical wage thresholds from bottom to top, using standard indifference conditions. At the end, the fraction $\mu$ is pinned down to ensure that disutility firms are indifferent between offering wages in the lower or in the upper wage range. We find that $\mu$ is positive if, and only if,

$$
d<d^{*} \equiv \frac{p \sigma}{\sigma+(1-\sigma)(1-\lambda)^{m}} .
$$

When the disutility parameter is larger than $d^{*}$, no disutility firm offers low wages, in which case $\mu=0$ and $\underline{w}_{0}=0$. On the other hand, it always holds that $\mu<1$; there must be some disutility firms rejecting B applicants, as has been explained above.

Figure 1 shows the wage-offer density in a numerical example where $p=1, d=.1$, $\sigma=\lambda=.5$ and $m=1$. Here the critical wage thresholds are $\underline{w}_{0} \approx .897, \underline{w}_{1}=.95$ and $\bar{w} \approx .953$. Fraction $1-\mu \approx 10.5 \%$ of disutility firms set high wages $w \in\left[\underline{w}_{1}, \bar{w}\right]$, rejecting $\mathrm{B}$ workers. Hence, in this example, the chance that a $\mathrm{B}$ worker ends up without a job-offer is merely $(\lambda(1-\mu))^{2} \approx 0.27 \%$. 


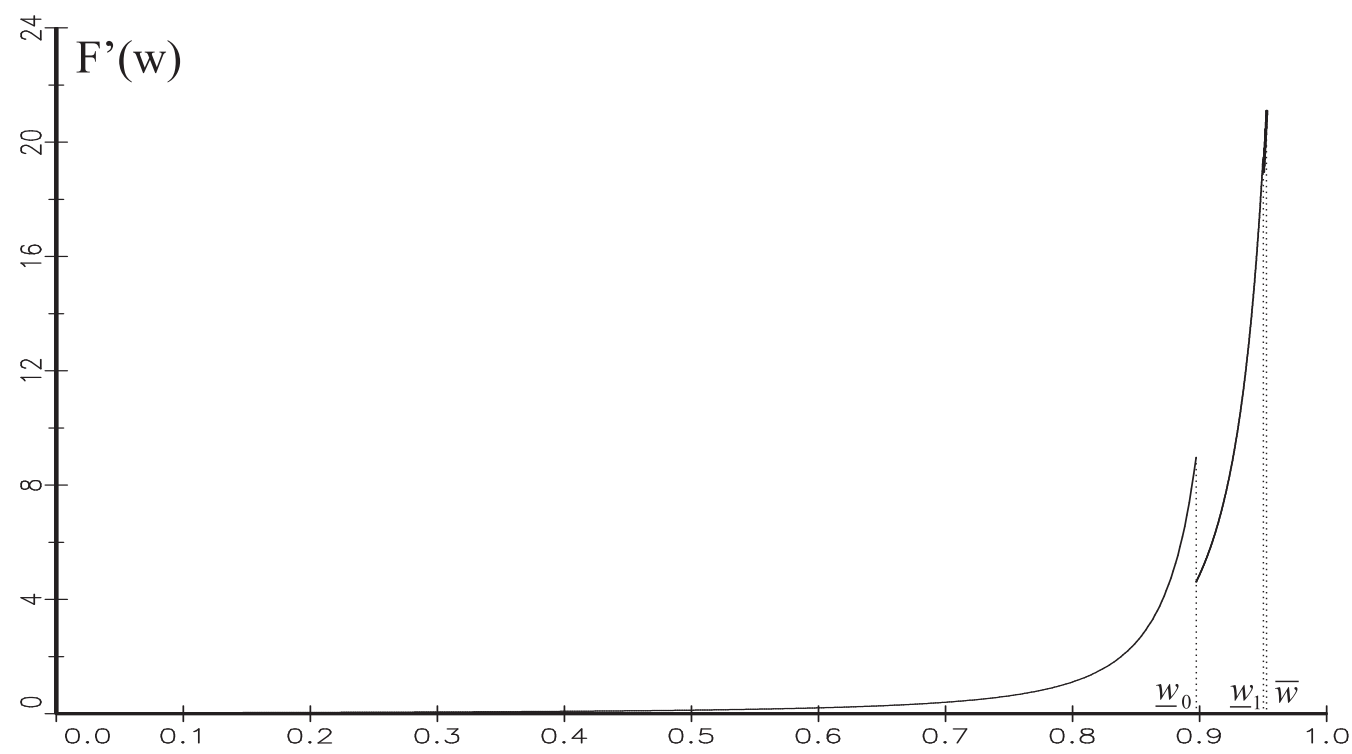

Figure 1: The equilibrium wage-offer density for parameters $p=1, d=.1, \lambda=\sigma=$ $.5, m=1$. About $89.5 \%$ of disutility firms offer wages $w \in[0, .897]$ and $10.5 \%$ of them offer wages $w \in[.95, .953]$, rejecting B workers.

Relative to the outcomes under laissez faire and under strict enforcement of pay and hiring equality, wage dispersion is much larger in this policy regime. In the absence of hiring discrimination, no firm is willing to offer wages below $w=p-d$ (under laissez faire) or below $w=p-\sigma d$ (under equal pay with affirmative action). With a reasonably small disutility taste parameter, wage dispersion is small since all wages are close to marginal product. Without enforcement of hiring equality, however, there are always firms who offer much lower wages and the support of the wage offer distribution is larger, certainly so when $d \leq p / 2,14$

Although overall wage dispersion increases, it is analytically intractable to answer what happens to the mean wages of workers in the two groups and to the wage gap between A and B workers, although it is obvious that a positive wage gap

\footnotetext{
${ }^{14}$ Nevertheless, in the limit $d \rightarrow 0$ the wage offer distribution converges to the Dirac distribution at $w=p$. Although the support of $F$ is still the full interval $[0, \bar{w}]$ with $\bar{w} \rightarrow p$, the variance becomes arbitrarily small in this limit.
} 
must remain. The next section sheds light on these questions with a few numerical examples. On the other hand, it is possible to show that payoffs of all firms are always higher than under laissez faire. And obviously, total welfare is reduced since some B workers do not find employment in this labor market.

Proposition 3: Under the equal-pay policy without affirmative action, a fraction $1-\mu>0$ of disutility firms rejects all $B$ workers and offers wages in some interval $\left[\underline{w}_{1}, \bar{w}\right]$. Provided that $d<d^{*}$, there is also a positive fraction $\mu$ of disutility firms offering wages $w \in\left[0, \underline{w}_{0}\right]$ who employ all workers. Nondisutility firms offer wages in the range $\left[\underline{w}_{0}, \underline{w}_{1}\right]$ where $\underline{w}_{0}>0$ iff $d<d^{*}$. Provided that $d \leq p / 2$, the support of the wage offer distribution is larger than under laissez-faire or under equal pay with equal opportunity of employment. Payoffs of all firms are higher than under laissez-faire.

\section{Mean wages and the wage gap}

In this section we analyze numerically whether the equal pay policy is effective in lowering wage inequality and raising wages for B workers. We also examine how the effectiveness of policy depends on the relative shares of minority workers and of disutility firms and on the degree of competition, as measured by $m$. If policy would magnify wage inequality between different demographic groups or reduce wages for B workers under certain conditions, policy makers should be more cautious to implement it.

In all numerical examples, we normalize workers' productivity to $p=1$ and we choose a reasonably small value of the disutility taste parameter at $d=.1$. In the Appendix we show how mean earnings can be calculated under laissez faire and under equal pay. If a B worker happens to send all applications to high-wage disutility firms rejecting him, we assume that this worker still finds employment in an outside labor market at his zero reservation wage. The alternative would be to treat these workers as unemployed; this would give rise to a higher conditional 
mean wage for employed B workers which, however, would not adequately reflect their impaired employment perspectives.

For the benchmark parameters of Figure 1, mean wages for the two worker groups are $E\left(w^{A}\right) \approx .92$ and $E\left(w^{B}\right)=.908$, so the wage gap is about $1.25 \%$. Compared with the laissez-faire outcome where $E\left(w^{A}\right)=1$ and $E\left(w^{B}\right)=.925$, the wage gap under the equal-pay policy is reduced to about one sixth. Nevertheless B workers are worse off, earning lower wages than under laissez faire. The standard deviations of earnings are reasonably low at $\sigma\left(w^{A}\right)=4.3 \%$ and $\sigma\left(w^{B}\right)=6.0 \%$. Although the support of the wage-offer distribution is larger for A workers, the standard deviation of earnings is higher for B workers since some of them end up earning a zero wage whereas the wage-offer distribution is skewed to the left. Under laissez faire, standard deviations are $\sigma\left(w^{A}\right)=0$ and $\sigma\left(w^{B}\right)=1.85 \%$. Hence both workers not only earn lower wages, they also face much higher income uncertainty.

To explore the role of parameters, Figure 2 shows what happens to mean earnings when $\sigma$ and $\lambda$ are varied from their benchmark at $\sigma=\lambda=.5$. For all parameters, B workers earn lower wages on average under the policy than under laissez faire. The left graph shows that the wage gap nearly vanishes when the share of $\mathrm{B}$ workers is large. In fact, in the limit $\sigma \rightarrow 1$, the common wage offer distribution under equal pay converges to the laissez-faire wage-offer distribution for $B$ workers. In the opposite situation of a small share of B workers, however, the wage gap between $\mathrm{A}$ and $\mathrm{B}$ workers widens substantially. The intuition is that wage competition for A workers becomes fiercer when the share of A workers increases, so A workers gain when their relative number increases. B workers lose however since more disutility firms decide to reject $\mathrm{B}$ applicants at high wages ( $\mu$ falls) so that a larger share of $\mathrm{B}$ workers do not find a job in this labor market and earn their zero reservation wage. When $\sigma$ is below .15, the wage gap under the equal pay policy is larger than under laissez faire. The right graph shows that wages for all workers fall under the policy when the share of disutility firms increases. Also the wage gap widens in this case, both under laissez faire and under the equal-pay policy.

A complete overview of the impact of $\sigma$ and $\lambda$ on the wage gap and on earnings for $\mathrm{B}$ workers is provided in Figure 3. Figure 3(a) demonstrates that the policy often 

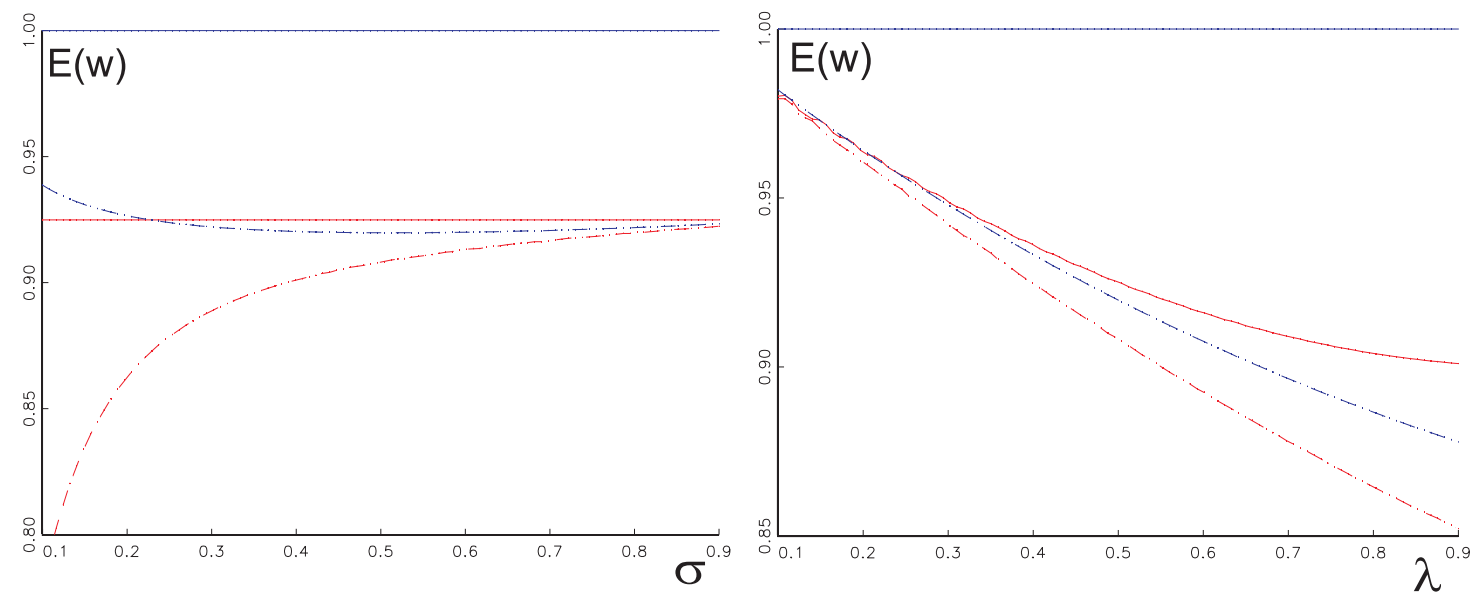

Figure 2: Mean earnings for A workers (blue) and B workers (red) under laissez faire (solid) and equal pay (dashed) as $\lambda$ and $\sigma$ are varied (all other parameters as in Figure 1).

does not succeed in reducing the wage gap between A and B workers. Moreover, its effectiveness is closely related to the proportion of minority workers and that of disutility firms in the market. If less than $20 \%$ of all workers are type B and a majority of firms have a disutility taste against these workers, the policy increases the wage gap. Nevertheless, for a large set of parameter constellations, the policy reduces the wage gap between $\mathrm{A}$ and $\mathrm{B}$ workers. However, what ultimately matters for discriminated workers is not the wage gap per se, but the policy impact on their expected earnings. To this end, Figure 3(b) shows the difference between the mean wage of B workers under laissez faire and under the equal-pay policy, again for different parameter configurations of $\sigma$ and $\lambda$. The mean wage of $\mathrm{B}$ workers is always reduced by the equal pay policy. Particularly, if the market is made up of less B workers and more disutility firms, the mean wage of minority workers falls substantially. Hence, our model predicts that if the labor market has a small proportion of minority workers and a large proportion of disutility firms, equal pay policy alone 
cannot be a good strategy from both the aspects of efficiency and equality. On the one hand, efficiency is impaired by the regulation. Without the policy regulation, all workers are employed by some firm with productivity $p$, but after the introduction of equal pay legislation, some $B$ workers do not find employment but rather receive their reservation wage income (either in unemployment or in an outside labor market). On the other hand, wage inequality is increased by the policy. Not only can the wage gap increase, but mean wages of discriminated workers are reduced by the policy. Within-group wage dispersion also increases substantially. Hence both equality and efficiency are harmed by equal-pay policy.
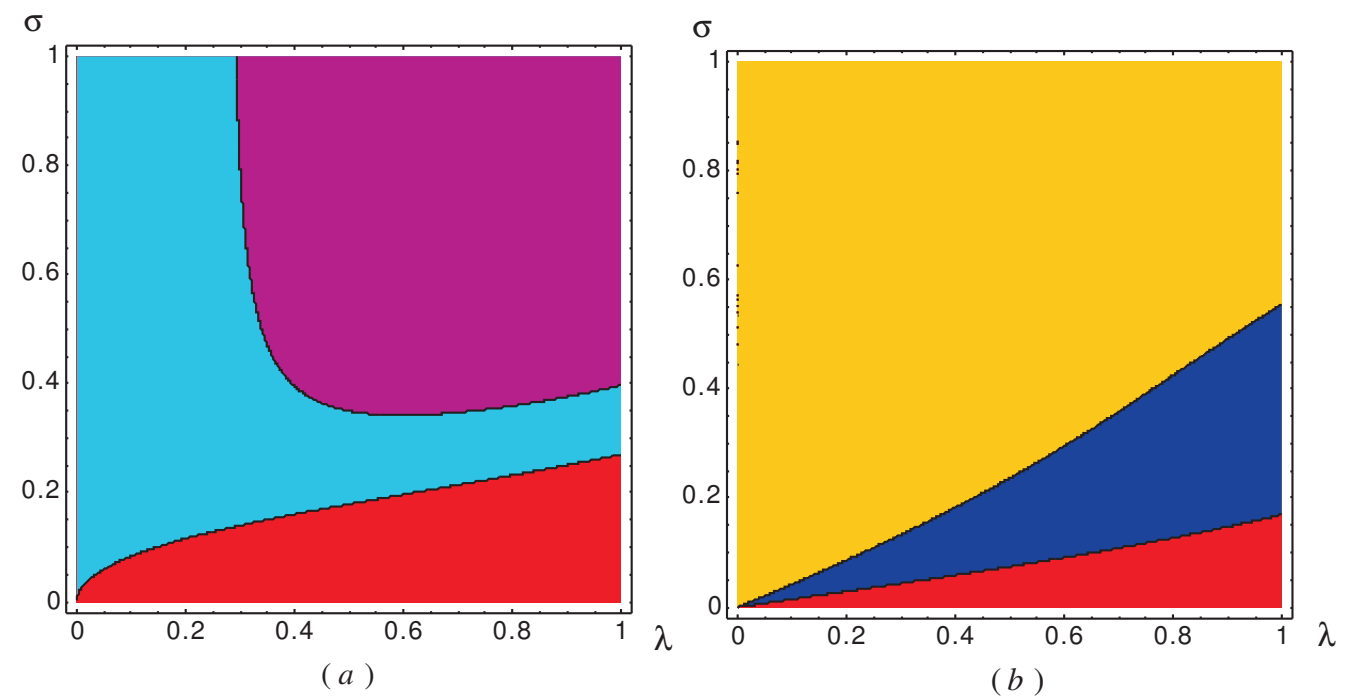

Figure 3: (a) Reduction of the wage gap under the policy (negative if wage gap increases, with red $<0$, blue $0-0.05$, purple $0.05-0.1$ ). (b) Reduction of mean earnings of $\mathrm{B}$ workers (yellow $0-0.05$, blue $0.05-0.2$, red $>0.2$ ). All other parameters are as in Figure 1.

Finally, we explore what happens to mean wages when the labor market is more "competitive" in the sense that the number of applications per worker increases. As we have argued before (footnote 10), a larger number of active firms increases the number of suitable job openings for each worker and so is likely to raise the number of applications. It is straightforward to show that all workers earn $w=p$ in the limit 
$m \rightarrow \infty$. Under laissez faire, the wage-offer distribution for B workers degenerates at the two values $w=p-d$ (offered by disutility firms) and $w=p$ (offered by nondisutility firms). All B workers are however employed by nondisutility firms in the limit. Under equal-pay policy, the wage-offer distribution again degenerates when $m \rightarrow \infty: \mu \rightarrow \lambda /(1+\lambda)$ disutility firms offer $w=p-d$, and all other disutility firms and nondisutility firms offer $w=p$. All workers again earn $w=p$ in the limit. Figure 4 confirms that mean earnings of all workers approach $p=1$ when the number of applications is increased from $1+m=2$ to $1+m=8$. For these benchmark parameters, the wage gap is always reduced but nevertheless B workers lose on average under the policy. The reduction of the wage gap is largest at lower values of $m$; that is, equal-pay policy is more effective in reducing the wage gap when the labor market is less competitive. In more competitive labor markets, however, the policy impact on the wage gap is negligible.

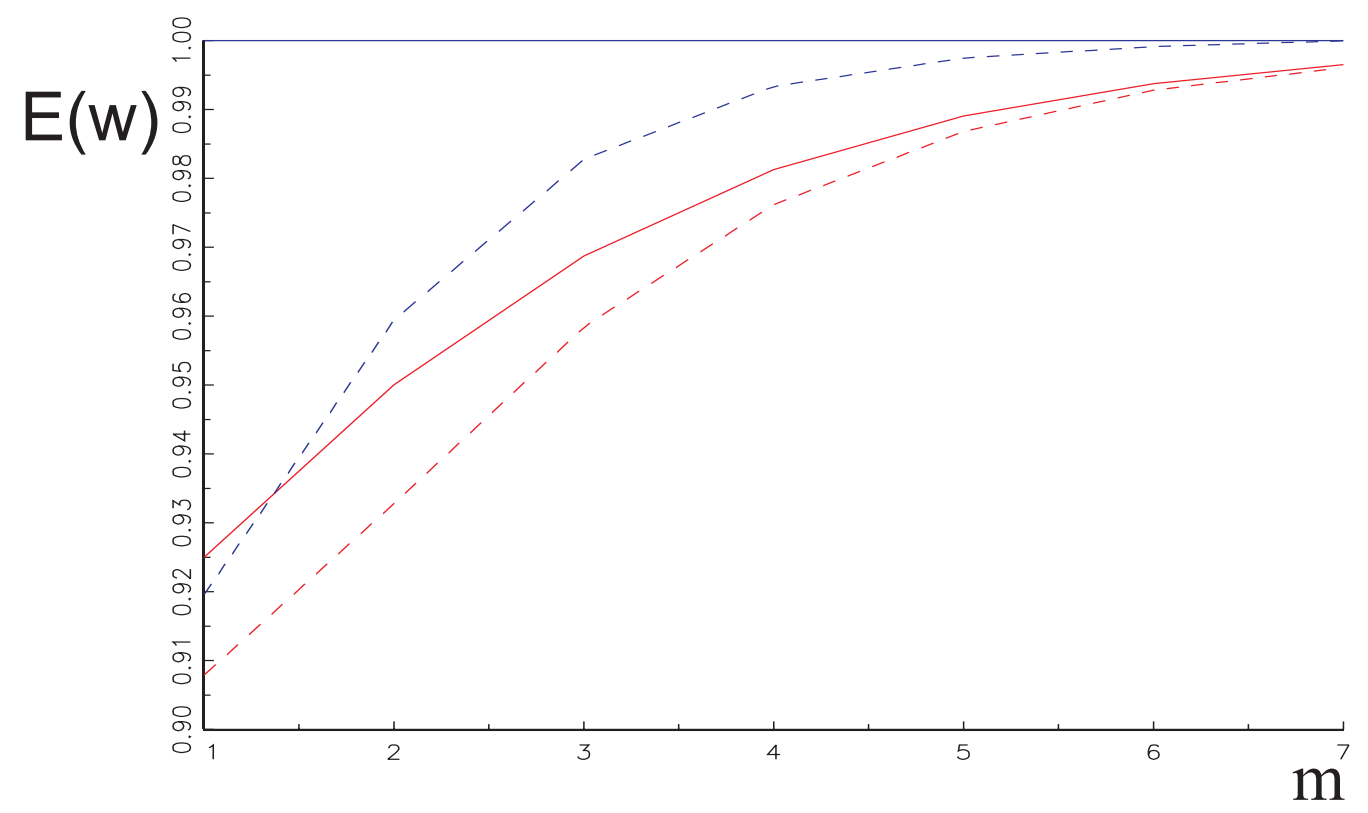

Figure 4: Mean earnings for A workers (blue) and B workers (red) under laissez faire (solid) and equal pay (dashed) as $m$ is increased (all other parameters as in Figure $1)$. 


\section{Conclusion}

The literature on labor search and discrimination has been successful in explaining the persistence of between-group wage differentials, but remains rather silent about policy implications. This paper sheds light on the impact of equal pay legislation in combination with and without affirmative action policy on the wage differential in the labor market. In a random search model with taste-based discrimination, it is shown that equal-pay policy is often not helpful in promoting wage equality. The key results of this paper can be summarized as follows.

- Under laissez faire, the existence of a discriminatory taste generates both between-group and within-group wage dispersion. Nevertheless, wage inequality is minor if the disutility parameter is small.

- If equal-pay legislation is supported by a strict affirmative action program, the policy succeeds in perfectly eliminating the wage differential between the two groups of workers. Within-group wage dispersion remains however. There is no negative impact on firms' profits or on welfare.

- In contrast, if affirmative action is not applicable, the policy causes discriminatory practices in hiring of some or all discriminators, which raises all employers' market power. Overall wage dispersion is amplified, even when the disutility taste is small. A positive wage gap remains which can be even larger than under laissez faire. Mean wages for minority workers are always lower. Both discriminating and non-discriminating firms gain from the policy, but welfare is reduced.

It is an open issue how far these policy implications extend to more general situations where the strength of affirmative action varies continuously between the two extremes discussed in this paper, as suggested in footnote [13, Whenever affirmative action is not perfect $(\gamma<1)$, some hiring discrimination must occur in equilibrium, and some firms then attempt to hire rejected $\mathrm{B}$ workers at their reservation wage; 
hence the support of the wage-offer distribution would again increase significantly under the policy.

\section{Appendix}

\section{Proof of the Lemma:}

Observe first that disutility firms must offer wages $w>p-d$ with positive probability (and thus reject B applicants), i.e. $F_{d}(p-d)<1$. Otherwise there would only be a zero mass of rejected B applicants, so hiring discrimination would be irrelevant, and equilibrium would be as in Proposition 2, which contradicts the absence of hiring discrimination (because of $p-\sigma d>p-d$ ). We proceed to prove the five claims of the Lemma sequentially.

Claim 1: $F$ is continuous (no mass points). It is obvious that there is no mass point at any wage $w \neq p-d$ and $w \neq p$ : If a positive mass of firms would offer such a wage, each of them could raise payoff by offering $w+\varepsilon$ with $\varepsilon$ sufficiently small. $w=p-d$ also cannot be a mass point. For the same reason as above, no mass of nondisutility firms will offer this wage. And if a mass of disutility firms would offer $w=p-d$, they only derive positive surplus from hiring A workers but zero payoff from $\mathrm{B}$ workers. Again any of these firms could raise payoff by offering $w+\varepsilon$ and rejecting $\mathrm{B}$ applicants. Finally, no firm offers $w=p$, since payoff would be zero whilst it is positive at $w=0$ where a firm can hire at least a positive mass of $\mathrm{B}$ applicants who are rejected elsewhere.

Claim 2: $F$ is strictly increasing (i.e. the support is connected). Suppose no firm sets a wage in the non-empty interval $\left(w_{0}, w_{1}\right), w_{1}$ is in the support of $F$, and $w_{0} \geq 0$. Then the firm offering $w_{1}$ can raise payoff by offering $w_{1}-\varepsilon$, hiring the same number of workers at lower cost.

Claim 3: The lower bound of the support of $F$ is zero. Suppose instead that $\underline{w}>0$ is the lower bound. Then a firm offering this wage can only hire those B workers whose other $m$ applications go to high-wage disutility firms (note that, because of Claim 1, the chance that another offer comes from a firm that also offers 
$\underline{w}$ is zero). But these workers can also be hired at $w=0$ at strictly higher payoff.

Claim 4: Let $w_{x}$ be in the support of $F_{x}, x=d, n$, and let $w_{d} \leq p-d$. Then $w_{d} \leq w_{n}$ holds. The proof is the same as in related wage dispersion models with productivity heterogeneity. From payoff maximization follows that

$$
\begin{aligned}
\left(p-w_{n}\right) \ell\left(w_{n}\right) & \geq\left(p-w_{d}\right) \ell\left(w_{d}\right) \\
\left(p-\sigma d-w_{d}\right) \ell\left(w_{d}\right) & \geq\left(p-\sigma d-w_{n}\right) \ell\left(w_{n}\right),
\end{aligned}
$$

where $\ell(w)$ is employment (of A and B workers), a strictly increasing function of the wage offer $w$ (from Claim 2). This implies that

$$
\left(p-w_{n}\right) \ell\left(w_{n}\right) \geq\left(p-w_{d}\right) \ell\left(w_{d}\right)>\left(p-\sigma d-w_{d}\right) \ell\left(w_{d}\right) \geq\left(p-\sigma d-w_{n}\right) \ell\left(w_{n}\right),
$$

from which follows that

$$
[p-(p-\sigma d)] \ell\left(w_{n}\right) \geq[p-(p-\sigma d)] \ell\left(w_{d}\right)
$$

Since $\sigma d>0$ and $\ell$ is increasing, $w_{n} \geq w_{d}$.

Claim 5: Let $w_{x}$ be in the support of $F_{x}, x=d, n$, and let $w_{d}>p-d$. Then $w_{d} \geq w_{n}$ holds. Suppose instead that $w_{d}<w_{n}$. Then there are three possibilities, all of which will lead to a contradiction.

First, there is an interval $I=\left(w_{d}, \tilde{w}\right)$ which belongs to the support of $F_{d}$ and not to the support of $F_{n}$, but $\tilde{w} \leq w_{n}$ belongs to the support of $F_{n}$. Second, an open interval $I=\left(w_{d}, \tilde{w}\right)$ belongs to the support of both $F_{n}$ and $F_{d}$. Third, there is an interval $I=\left(w_{d}, \tilde{w}\right)$ belonging to the support of $F_{n}$ but not to the support of $F_{d}$, for some $\tilde{w} \leq w_{n}$. There is no further possibility since the support of $F$ is connected (claim 2).

Suppose the first possibility was true. Then, for all $w \in I$, disutility firms are indifferent between offering $w$ or $\tilde{w}$ (note that all payoff functions are continuous since the wage-offer distribution is continuous), and they do not hire B workers, so

$$
(p-w) \ell^{A}(w)=(p-\tilde{w}) \ell^{A}(\tilde{w})
$$


But then the nondisutility firm offering $\tilde{w}$ can do strictly better by offering $w \in I$ instead:

$$
\begin{aligned}
(p-\tilde{w})\left[\ell^{A}(\tilde{w})+\ell^{B}(\tilde{w})\right] & =(p-w) \ell^{A}(w)+(p-\tilde{w}) \ell^{B}(\tilde{w}) \\
& <(p-w) \ell^{A}(w)+(p-w) \ell^{B}(\tilde{w}) \\
& =(p-w)\left[\ell^{A}(w)+\ell^{B}(w)\right]
\end{aligned}
$$

where the last equation uses $\ell^{B}(\tilde{w})=\ell^{B}(w)$ because only disutility firms (who reject B workers) offer wages in $I$ and since the mass of nondisutility firms offering $\tilde{w}$ is zero (claim 1).

Second, suppose the supports of $F_{d}$ and $F_{n}$ overlap on some open interval $I$. Then, the payoff function of a disutility firm, $(p-w) \ell^{A}(w)$, and the one of a nondisutility firm, $(p-w) \ell(w)$ (with $\ell(w)=\ell^{A}(w)+\ell^{B}(w)$ ) are both constant (and thus differentiable) at any $w \in I$, satisfying

$$
\begin{aligned}
\ell(w) & =(p-w) \ell^{\prime}(w), \\
\ell^{A}(w) & =(p-w) \ell^{A^{\prime}}(w),
\end{aligned}
$$

which also implies that

$$
\ell^{B}(w)=(p-w) \ell^{B^{\prime}}(w)
$$

Labor supply of A and B workers to a firm offering $w>p-d$ is

$$
\begin{aligned}
& \ell^{A}(w)=\frac{(1+m)(1-\sigma)}{N}\left[\lambda F_{d}(w)+(1-\lambda) F_{n}(w)\right]^{m}, \\
& \ell^{B}(w)=\frac{(1+m) \sigma}{N}\left[\lambda+(1-\lambda) F_{n}(w)\right]^{m} .
\end{aligned}
$$

In the last equation, a B worker sends another application to a disutility firm with probability $\lambda$. This firm either makes an offer at a wage below $p-d$, or rejects the worker. Thus none of these applications result in an offer which is preferred to $w$. Rewriting (4) and (5) using (6) and (7) yields

$$
\begin{aligned}
\lambda F_{d}(w)+(1-\lambda) F_{n}(w) & =(p-w) m\left[\lambda F_{d}^{\prime}(w)+(1-\lambda) F_{n}^{\prime}(w)\right], \\
\lambda+(1-\lambda) F_{n}(w) & =(p-w) m(1-\lambda) F_{n}^{\prime}(w) .
\end{aligned}
$$


Subtracting (9) from (8) gives

$$
F_{d}(w)-1=(p-w) m F_{d}^{\prime}(w),
$$

which is a contradiction since the left-hand side is strictly negative (because $w$ is in the interior of $\left.I \subset \operatorname{supp} F_{d}\right)$ and the right-hand side is non-negative.

Lastly, suppose the third possibility was true. Then, for all $w \in I=\left(w_{d}, \tilde{w}\right)$, nondisutility firms are indifferent between offering $w$ or $w_{d}$; hence (3) holds for all $w \in I$. While labor supply of B workers to any $w \in I$ is again (7), labor supply of A workers is

$$
\ell^{A}(w)=\frac{(1+m)(1-\sigma)}{N}\left[\lambda F_{d}\left(w_{d}\right)+(1-\lambda) F_{n}(w)\right]^{m},
$$

since no disutility firm offers a wage $w \in I=\left(w_{d}, \tilde{w}\right)$. Equation (3) can be expressed as

$$
(1-\sigma) x_{A}^{m}+\sigma x_{B}^{m}=(p-w) m(1-\lambda) F_{n}^{\prime}(w)\left[(1-\sigma) x_{A}^{m-1}+\sigma x_{B}^{m-1}\right],
$$

with

$$
x_{A} \equiv \lambda F_{d}\left(w_{d}\right)+(1-\lambda) F_{n}(w) \text { and } x_{B} \equiv \lambda+(1-\lambda) F_{n}(w) .
$$

From (10) and $x_{B} \geq x_{A}$ follows that

$$
(p-w) m(1-\lambda) F_{n}^{\prime}(w)=\frac{(1-\sigma) x_{A}^{m}+\sigma x_{B}^{m}}{(1-\sigma) x_{A}^{m-1}+\sigma x_{B}^{m-1}} \geq(1-\sigma) x_{A}+\sigma x_{B} .
$$

On the other hand, the slope of the payoff function of disutility firms at any $w \in I$ is

$$
\begin{aligned}
\frac{N}{(1+m)} \frac{d}{d w}(p-w) \ell^{A}(w) & =-(1-\sigma) x_{A}^{m}+(1-\sigma)(p-w) m(1-\lambda) F_{n}^{\prime}(w) x_{A}^{m-1} \\
& =(1-\sigma) x_{A}^{m-1}\left[-x_{A}+(p-w) m(1-\lambda) F_{n}^{\prime}(w)\right] \\
& \geq(1-\sigma) \sigma x_{A}^{m-1}\left[x_{B}-x_{A}\right] \\
& =(1-\sigma) \sigma x_{A}^{m-1} \lambda\left[1-F_{d}\left(w_{d}\right)\right],
\end{aligned}
$$

where the third line uses (11). Now there are two possible cases. Either the last term is strictly positive which is a contradiction since then disutility firms could 
raise payoff by deviating from $w_{d}$ to $w>w_{d}$. Or the last term is zero which implies $F_{d}\left(w_{d}\right)=1$. But then there must be a positive mass of disutility firms offering wages in another open interval $\hat{I} \subset\left(p-d, w_{d}\right)$, so that one of the other two possibilities above (which also lead to contradictions) must apply.

This completes the proof of the Lemma.

\section{Proof of Proposition 3:}

Consider a given $\mu$ (to be determined below) and consider the wage-offer distribution for low-wage disutility firms. These firms are indifferent between offering any wage $w \in\left[0, \underline{w}_{0}\right]$, or the zero reservation wage, at which they hire only those B applicants who send all other applications to a high-wage disutility firm where they are rejected:

$$
\begin{aligned}
& (p-d-w) \frac{(1+m) \sigma}{N}\left[\lambda(1-\mu)+\lambda \mu F_{d}^{l}(w)\right]^{m}+(p-w) \frac{(1+m)(1-\sigma)}{N}\left[\lambda \mu F_{d}^{l}(w)\right]^{m} \\
= & (p-d-0) \frac{(1+m) \sigma}{N}[\lambda(1-\mu)]^{m} .
\end{aligned}
$$

Note that in this expression, as in all the other indifference conditions below, the terms $(1+m) / N$ cancel out on both sides. To save on notation, we therefore skip these terms in all the other equations in this proof. The wage-offer distribution $F_{d}^{l}$ cannot be solved analytically, except for low values of $m$. For example, with $m=1$ we have

$$
F_{d}^{l}(w)=\frac{w}{p-d \sigma-w} \cdot \frac{\lambda \sigma(1-\mu)}{\lambda \mu} .
$$

For larger values of $m, F_{d}^{l}$ is a strictly increasing and convex function, and the upper bound is obtained from $F_{d}^{l}(w)=1$ as

$$
\underline{w}_{0}=\frac{p\left[\sigma\left(1-(1-\mu)^{m}\right)+(1-\sigma) \mu^{m}\right]-d \sigma\left[1-(1-\mu)^{m}\right]}{\sigma+(1-\sigma) \mu^{m}} .
$$

Wages in the medium range $w \in\left[\underline{w}_{0}, \underline{w}_{1}\right]$ are offered by nondisutility firms. Here the indifference condition (dropping $(1+m) / N)$ is that

$(p-w)\left\{\sigma\left[\lambda+(1-\lambda) F_{n}(w)\right]^{m}+(1-\sigma)\left[\lambda \mu+(1-\lambda) F_{n}(w)\right]^{m}\right\}=\left(p-\underline{w}_{0}\right)\left[\sigma \lambda^{m}+(1-\sigma)(\lambda \mu)^{m}\right]$. 
The analytical solution when $m=1$ is

$$
F_{n}(w)=\frac{w-\underline{w}_{0}}{p-w} \cdot \frac{(1-\sigma) \lambda \mu+\sigma \lambda}{1-\lambda} .
$$

The upper bound follows for arbitrary $m$ from $F_{n}\left(\underline{w}_{1}\right)=1$ together with (12) as

$$
\underline{w}_{1}=\frac{p\left[\sigma\left(1-(\lambda(1-\mu))^{m}\right)+(1-\sigma)(1-\lambda(1-\mu))^{m}\right]-d \sigma \lambda^{m}\left[1-(1-\mu)^{m}\right]}{\sigma+(1-\sigma)[1-\lambda(1-\mu)]^{m}} .
$$

In the highest wage range $\left[\underline{w}_{1}, \bar{w}\right]$, the remaining $1-\mu$ fraction of disutility firms are active. Because of $\underline{w}_{1}>p-d$ (as we show below), they reject all B applicants, so their indifference condition amounts to

$$
(p-w)(1-\sigma)\left[\lambda \mu+1-\lambda+\lambda(1-\mu) F_{d}^{h}(w)\right]^{m}=\left(p-\underline{w}_{1}\right)(1-\sigma)(\lambda \mu+1-\lambda)^{m}
$$

so that

$$
F_{d}^{h}(w)=\frac{\lambda \mu+1-\lambda}{\lambda(1-\mu)}\left[\left(\frac{p-\underline{w}_{1}}{p-w}\right)^{1 / m}-1\right] .
$$

From $F_{d}^{h}(\bar{w})=1$ and (13) follows the upper bound

$\bar{w}=\frac{p\left[\sigma+(1-\lambda(1-\mu))^{m}\left(1-\sigma-\sigma \lambda^{m}(1-\mu)^{m}\right)\right]-d \sigma \lambda^{m}(1-\lambda+\lambda \mu)^{m}\left(1-(1-\mu)^{m}\right)}{\sigma+(1-\sigma)(1-\lambda(1-\mu))^{m}}$.

Finally, the unknown variable $\mu$ follows from the requirement that payoff of all disutility firms must be the same. Provided that $\mu \in(0,1)$, this is satisfied whenever the disutility firm offering $w=0$ gets the same payoff as the one that offers $\bar{w}$ and hires only A applicants (rejecting all B applicants):

$$
(p-d-0) \sigma \lambda^{m}(1-\mu)^{m}=(p-\bar{w})(1-\sigma) .
$$

Using (14) and solving yields

$$
\mu=\frac{\left(\frac{(p-d) \sigma}{d(1-\sigma)}\right)^{1 / m}+\lambda-1}{\left(\frac{(p-d) \sigma}{d(1-\sigma)}\right)^{1 / m}+\lambda}
$$


Clearly, $\mu<1$ is always satisfied when there are some A workers $(\sigma<1) 15$ However, the presence of disutility firms offering low wages $(\mu>0)$ and hiring $\mathrm{B}$ workers requires that the disutility taste parameter is not larger than $d^{*}$. When $d \geq d^{*}$, all disutility firms offer high wages and reject $\mathrm{B}$ applicants who are then either hired by a nondisutility firm or do not get a job if they happen to send all applications to disutility employers.

It can also be confirmed that the derived wage thresholds (12) and (13) are indeed compatible with the assumed hiring behavior of disutility firms. When $d \geq d^{*}$, $\underline{w}_{0}=0$ and

$$
\underline{w}_{1}=\frac{p\left[\sigma\left(1-\lambda^{m}\right)+(1-\sigma)(1-\lambda)^{m}\right]}{\sigma+(1-\sigma)(1-\lambda)^{m}}>p-d .
$$

And when $d<d^{*}$, some algebra yields $\underline{w}_{1}=p-d \lambda^{m} \geq p-d$, and $\underline{w}_{0}<p-d$ is equivalent to $\mu(1-\lambda)<1-\lambda$ which is true whenever $\lambda<1$ (since $\mu<1$ ). In the limit $\lambda \rightarrow 1$ (no nondisutility firms), both thresholds obviously collapse at $w=p-d$. When workers send only two applications $(m=1)$, the combined market wage offer distribution $F(w)=\lambda \mu F_{d}^{l}(w)+(1-\lambda) F_{n}(w)+\lambda(1-\mu) F_{d}^{h}(w)$ is

$$
F(w)=\left\{\begin{array}{ll}
\frac{w \lambda \sigma(1-\mu)}{p-d \sigma-w} \quad, w \in\left[0, \underline{w}_{0}\right] \\
\lambda \mu+\frac{\left(w-\underline{w}_{0}\right)[(1-\sigma) \lambda \mu+\sigma \lambda]}{p-w} \\
\lambda \mu+1-\lambda+\frac{\left(w-\underline{w}_{1}\right)(1-\lambda+\lambda \mu)}{p-w}
\end{array}, w \in\left[\underline{w}_{0}, \underline{w}_{1}\right]\right.
$$

It remains to prove the results on firm payoffs and profits. Suppose that $d<d^{*}$ (the other case is similar). Consider disutility firms first. Their payoff is

$$
U^{d}=\frac{(1+m) \sigma}{N}(p-d-0) \lambda^{m}(1-\mu)^{m}>0
$$

so it is greater than the zero payoff under laissez faire. Profits, however, differ among disutility firms: low-wage firms employ B workers so their profits are larger than profits of high-wage firms that do not employ B workers. In fact, profit is lowest at $\pi_{\text {min }}^{d}=U^{d}$ at any high-wage disutility firm offering $w>p-d$, and highest at the

\footnotetext{
${ }^{15}$ In the limit $\sigma \rightarrow 1$, there is only competition for $B$ workers, and the equilibrium distribution converges to the one derived in Section 3 where all disutility firms offer $w=p-d$.
} 
disutility firm offering $w=0$ where profit is

$$
\pi_{\max }^{d}=\frac{(1+m) \sigma}{N} p \lambda^{m}(1-\mu)^{m}
$$

On the other hand, profit under laissez faire is $\pi_{L F}^{d}=\sigma \lambda^{m} d / N$. It is straightforward to show that there are parameters where $\pi_{\text {max }}^{d}>\pi_{L F}^{d}>\pi_{\text {min }}^{d}$, so profits of disutility firms can be higher or lower. Now consider nondisutility firms. For $d<d^{*}$, the highest wage they offer is $\underline{w}_{1}=p-d \lambda^{m}$, so their payoff (=profit) is

$$
U^{n}=\left[p-\left(p-d \lambda^{m}\right)\right] \frac{1+m}{N}\left\{\sigma+(1-\sigma)[\lambda \mu+1-\lambda]^{m}\right\} .
$$

But this is clearly larger than payoff (=profit) under laissez faire, $U_{L F}^{n}=(1+$ $m) \sigma \lambda^{m} d / N$.

\section{Calculation of mean wages under laissez faire}

Workers of type A face a degenerate wage offer distribution that concentrates all mass at $w_{A}=p$.

B workers either send all $1+m$ applications to disutility firms, in which case they get $w=p-d$, or they send $1 \leq k \leq 1+m$ applications to nondisutility firms who offer wages drawn from distribution $F_{n}^{B}(w)=\left(F^{B}(w)-\lambda\right) /(1-\lambda)$. Hence,

$$
\begin{aligned}
E\left(w_{B}\right) & =\lambda^{1+m}(p-d)+\sum_{k=1}^{1+m}\left(\begin{array}{c}
m+1 \\
k
\end{array}\right) \lambda^{m+1-k}(1-\lambda)^{k} \int_{p-d}^{p-d \lambda^{m}} w d F_{n}^{B}(w)^{k} \\
& =\lambda^{1+m}(p-d)+\int_{p-d}^{p-d \lambda^{m}}(1+m) \sum_{\ell=0}^{m}\left(\begin{array}{c}
m \\
\ell
\end{array}\right) \lambda^{m-\ell}\left(F^{B}(w)-\lambda\right)^{\ell} w F^{B^{\prime}}(w) d w \\
& =\lambda^{1+m}(p-d)+(1+m) \int_{p-d}^{p-d \lambda^{m}} w F^{B^{\prime}}(w) F^{B}(w)^{m} d w
\end{aligned}
$$

\section{Calculation of mean wages under the equal-pay policy without affirmative action}

The mean wage of $\mathrm{A}$ workers is

$$
E\left(w_{A}\right)=\int_{0}^{\bar{w}} w d F(w)^{1+m}=(1+m) \int_{0}^{\bar{w}} w F^{\prime}(w) F(w)^{m} d w
$$


B workers earn a zero wage with probability $(\lambda(1-\mu))^{1+m}$. Otherwise, they draw $1 \leq k \leq 1+m$ wage offers from distribution $F$ on $\left[0, \underline{w}_{1}\right]$. But this is the same as if they draw all $1+m$ wage offers from the cumulative distribution $\tilde{F}(w) \equiv$ $\lambda(1-\mu)+F(w)$ which has a mass point at $w=0$ and support $\left[0, \underline{w}_{1}\right]$. Hence,

$E\left(w_{B}\right)=\int_{0}^{\underline{w}_{1}} w d[\lambda(1-\mu)+F(w)]^{1+m}=(1+m) \int_{0}^{\underline{w}_{1}} w F^{\prime}(w)[\lambda(1-\mu)+F(w)]^{m} d w$.

\section{References}

Arrow, K. (1973): "The Theory of Discrimination," in Discrimination in Labor Markets, ed. by O. Ashenfelter, and A. Rees. Princeton University Press, Princeton, NJ.

Becker, G. (1957): The Economics of Discrimination. University of Chicago Press, Chicago.

Bertrand, M., and S. Mullainnathan (2004): "Are Emily and Greg more Employable than Lakisha and Jamal? A Field Experiment on Labor Market Discrimination," American Economic Review, 94, 991-1013.

Bisping, T., And J. FAin (2000): "Job Queues, Discrimination, and Affirmative Action," Economic Inquiry, 38, 123-135.

Black, D. A. (1995): "Discrimination in an Equilibrium Search Model," Journal of Labor Economics, 13, 309-334.

Bowlus, A., And Z. ECKstein (2002): "Discrimination and Skill Differences in an Equilibrium Search Model," International Economic Review, 43, 1309-1345.

Burdett, K., And K. Judd (1983): "Equilibrium Price Dispersion," Econometrica, 51, 955-969.

Burdett, K., and D. Mortensen (1998): "Wage Differentials, Employer Size, and Unemployment," International Economic Review, 39, 257-273. 
CAIn, G. (1986): "The Economic Analysis of Labor Market Discrimination: A Survey" in Handbook of Labor Economics, ed.by O.Ashenfelter, and R. Layard. vol.1, chap. 13 North-Holland, Amsterdam.

Conte, S., and G. Loury (1993): "Will Affirmative-Action Policies Eliminate Negative Stereotypes?," American Economic Review, 85, 1220-1240.

Holzer, H., And D. Neumark (2000): “Assessing Affirmative Action," Journal of Economic Literature, 38, 483-568.

KAAs, L. (2009): "Does Equal Pay Legislation Reduce Labour Market Inequality?," Scandinavian Journal of Economics, 111, 51-71.

Lang, K., M. Manove, and W. Dickens (2005): "Racial Discrimination in Labor Markets with Posted Wage Offers," American Economic Review, 95, 13271340 .

Lundberg, S., and R. Startz (1983): "Private Discrimination and Social Intervention in Competitive Labor Markets," American Economic Review, 73, 340-347.

Neumark, D., R. Bank, and K. V. Nort (1996): "Sex Discrimination in Restaurant Hiring: An Audit Study," Quarterly Journal of Economics, 111, 915-941.

Neumark, D., And W. Stock (2001): “The Effects of Race and Sex Discrimination Laws," NBER Working Paper 8215.

Phelps, E. (1972): "The Statistical Theory of Racism and Sexism," American Economic Review, 62, 659-661.

Riach, P., AND J. Rich (2002): "Field Experiments of Discrimination in the Market Place," The Economic Journal, 112, F480-F518.

Rogerson, R., R. Shimer, and R. Wright (2005): "Search-Theoretic Models of the Labor Market: a Survey," Journal of Economic Literature, 43, 958-988.

Rosen, A. (2003): "Search, Bargaining, and Employer Discrimination," Journal of Labor Economics, 21, 807-829. 
SHI, S. (2006): "Wage Differentials, Discrimination and Efficiency," European Economic Review, 50, 849-875.

Welch, F. (1976): "Employment Quotas for Minorities," Journal of Political Economy, 84, S105-S139. 